\title{
Nanophotonics
}

SPIEDigitalLibrary.org/jnp

\section{Editorial: Qui payes?}

\author{
Akhlesh Lakhtakia
}




\title{
Editorial: Qui payes?
}

\author{
Akhlesh Lakhtakia \\ Editor-in-Chief
}

Much, but not all, research today is financially supported by governments. In democratic dispensations, that means that a significant portion of research is funded by the taxpayers. Since the taxpayers have paid for the research upfront, should they not receive the research results for free? This argument underlies the concept of open-access publication of research results that is being increasingly demanded by governments and public-interest groups.

The publication of research results is, however, a commercial activity. Leave aside peer review, which is largely done pro bono. Manuscripts have to be copyedited and then published in archival forms. Whether commercial or non-profit, publishers have therefore to be compensated financially for publishing, storing, and disseminating research papers.

Who will pay the publishers? The taxpayers through additional research subsidies? The research institutions through overhead charges they levy on research sponsors?

A substantial number of research papers emerge from unsponsored research. Should the authors themselves pay for open-access publication? Why not have the readers of the journals continue to pay instead, as they have been doing for more than two centuries?

SPIE has confronted these and related issues for several years, and decided in favor of a flexible approach. Therefore, the Journal of Nanophotonics (JNP) has a new benefit for authors who support the journal through payment of voluntary page charges. Starting in January 2013, research articles for which such page charges are paid will be open access at publication. Open access will enable anyone to read a paper online at no charge and should lead to more awareness of its authors' research and may result in more citations.

The voluntary page charge is $\$ 60$ per published page. Payment of $\$ 360$ for a six-page letter article or $\$ 720$ to $\$ 840$ for a full research article of average length will result in immediate open access. Authors will retain copyright for open access articles through a Creative Commons attribution license (CC-BY "gold open access"; see http://creativecommons.org/licenses/by/3.0/). This is the type of license that many employers and research-funding agencies prefer or require.

All review and tutorial articles will be published with open access, even if the voluntary page charges are not paid.

Authors who lack the funds for open-access publication may continue to publish articles that will be freely available to the journal's many individual and institutional subscribers. These articles will be covered by SPIE's generous copyright transfer policy.

0091-3286/2012/\$25.00 @ 2012 SPIE 